\title{
G protein signaling controls the differentiation of multiple cell lineages
}

\author{
Kepeng Wang and Yung H. Wong*
}

Department of Biochemistry, the Molecular Neuroscience Center, and the Biotechnology Research Institute, Hong Kong University of Science and Technology, Clear Water Bay, Kowloon, Hong Kong, China.

* To whom correspondence should be addressed: Department of Biochemistry, Hong Kong University of Science and Technology, Clear Water Bay, Kowloon, Hong Kong, China.

Tel: (852) $23587328 \quad$ Fax: (852) 23581552

Email: boyung@ust.hk

Running title: GPCR signaling in cellular differentiation

Key words: G protein-coupled receptor, differentiation, neuron, blood, adipocyte, smooth muscle cell, osteoblast. 


\begin{abstract}
G protein-coupled receptors (GPCRs) detect a great diversity of extracellular stimuli ranging from hormonal peptides, chemokines, neurotransmitters, lipids, nucleotides, amino acids, biogenic amines to ions. G protein-coupled pathways regulate a rich collection of biological processes involved in normal physiological function of the body as well as in pathological progression of diseases. In addition to their function in post-mitotic steady-state tissues, GPCRs have been implicated in the differentiation of stem cells and tissue specific progenitor cells during development. Examples of these include the functions of nucleotides and neuropeptides in neuronal differentiation and axon growth, chemokines in lymphocyte differentiation and activation, and other GPCR-mediated processes in the differentiation of adipocytes, osteoblasts and smooth muscle cells. This review summarizes the recent advances in our understanding of the importance of GPCR-linked signaling cascades in the differentiation of different cell lineages.
\end{abstract}




\section{GPCR signaling}

The heptahelical G protein-coupled receptors (GPCRs) represent the largest family of receptors in human, mouse, worm and fly. Based on the human genome information, there may be as many as 700-800 human GPCRs [1]. Signaling by GPCRs mediates perception of light, tastes and odorants. Moreover, members of the GPCR family regulate intercellular signaling machineries by sensing extracelluar signals such as hormones, neurotransmitters, chemokines and ions. As a consequence of their extreme diversity, GPCRs regulate a huge collection of physiological processes. Accordingly, more than $30 \%$ of our current pharmaceutical agents act as agonists or antagonists of GPCRs [1].

GPCRs transduce extracelluar signals through the activation of heterotrimeric G proteins. Agonist activation of GPCRs induces conformational change on the receptors, which subsequently serve as guanine nucleotide exchange factors (GEFs) and induce the exchange of GDP to GTP on the Ga subunits of heterotrimeric G proteins. GTP binding and activation of four classes of G proteins lead to stimulation of complex intracellular signaling networks. These include stimulation of adenylyl cyclase and production of cyclic AMP (cAMP) by $\mathrm{G} \alpha_{\mathrm{s}}$, repression of cAMP production but stimulation of Src tyrosine kinase by members of activated $\mathrm{G}_{i}$ proteins, activation of phospholipase $\mathrm{C} \beta$ (PLC $\beta$ ) and subsequent release of intracellular $\mathrm{Ca}^{2+}$ by $\mathrm{G}_{\mathrm{q}}$ family, and RhoGEF activation by $\mathrm{G}_{12 / 13}[2-4]$. Numerous studies have focused on the function of $\mathrm{G}$ protein signaling in differentiated, post-mitotic cells. Prominent examples include the function and regulation of neurotransmitter receptors in the 
nervous system [5], chemokines in leukocyte attraction and cancer [6], and a variety of GPCRs in the regulation of smooth and cardiac muscle contraction [7]. These areas have been extensively covered by other reviews and will not be elaborated in this article. Instead, we set out to assimilate our current knowledge of the function of $\mathrm{G}$ protein-linked signaling pathways in cellular differentiation, and discuss the molecular basis of such regulation in different cell lineages.

\section{The functions of $G$ protein signaling in neuronal differentiation}

Neuronal differentiation and survival are coordinated by receptor tyrosine kinases and GPCR signaling pathways. Nerve growth factor (NGF) signals through TrkA and downstream ERK and Akt to promote neuronal survival and differentiation [8]. NGF-induced neuronal survival and differentiation can be potentiated by activating the $\mathrm{G}_{\mathrm{q}}$-coupled purinergic P2Y2 receptor $[9,10]$. ATP $\gamma \mathrm{S}$-treated PC12 cells and dorsal root ganglion (DRG) neurons exhibited enhanced neurite formation, whereas geneticor siRNA-mediated depletion of $\mathrm{P} 2 \mathrm{Y} 2$ receptors abolished this effect [9]. Binding of ATP to P2Y2 activates $\mathrm{G}_{\mathrm{q}}$ and PLC- $\beta$, leading to the production of inositol 1,4,5-trisphosphate $\left(\mathrm{IP}_{3}\right)$ and rapid $\mathrm{Ca}^{2+}$ influx. Increase in $\mathrm{Ca}^{2+}$ concentration activates $\mathrm{Ca}^{2+}$-calmodulin-dependent protein kinase (CaMK) and calcineurin, and their downstream transcription factors including brain-derived neurotrophic factor (BDNF) and myocyte enhancer factor 2A (MEF2A) that are important for neuronal development [11]. Interestingly, P2Y2 also appears to transactivate TrkA receptor to induce neuronal differentiation, as it colocalizes with TrkA and enhances NGF 
sensitivity [9]. Src family kinase (SFK) has been reported to mediate P2Y2 activation on TrkA receptor [12]. P2Y2 and TrkA synergistically prevent neuronal apoptosis in a similar mechanism [10]. Importantly, activation of purinergic receptors transmits complex communication between neurons and glials in adult brain [13]. It is not surprising to uncover that the same signaling mechanism is utilized during the developmental process of the nervous system.

Signaling through $\mathrm{G}_{\mathrm{i} / \mathrm{o}}$-coupled muscarinic acetylcholine receptors appears to cooperate with NGF in activating the PI3K/Akt pathway and promoting neuronal survival [14-16]. Treatment of PC12 cells with pertussis toxin (PTX; which inactivates $\mathrm{G}_{\mathrm{i} / \mathrm{o}}$ ) reduced NGF-induced Akt phosphorylation, but has no effect on the Akt response elicited by epidermal growth factor (EGF). The induction of PI3K/Akt pathway by NGF is in part mediated through the G $\beta \gamma$ subunit released from activated $\mathrm{G}_{\mathrm{i} / \mathrm{o}}$, which promotes the phosphorylation of translation regulator tuberlin to enhance neuronal survival $[14,15]$. In a similar manner, $\mathrm{G}_{\mathrm{i} / \mathrm{o}}$ mediates part of the NGF-induced p38 and JNK phosphorylations, which are required for neuronal differentiation [17, 18]. These examples suggest bidirectional crosstalk between GPCR and NGF signaling in the regulation of neuronal survival and differentiation.

In addition to nucleotide signaling, neuropeptides act through their GPCRs to regulate neuronal differentiation and brain development. Pituitary adenylyl cyclase-activating polypeptide (PACAP) and vasoactive intestinal peptide (VIP) act via VPAC1 and VPAC2 GPCRs [19]. Activation of VPAC1 and VPAC2 induces $\mathrm{G}_{\mathrm{s}}$-mediated cAMP production, as well as $\mathrm{G}_{\mathrm{q}}$-mediated $\mathrm{IP}_{3}$ production and calcium 
mobilization [20]. The effect of PACAP in neuronal cell proliferation remains controversial and is likely dependent on the receptor isoform expressed on target neurons [21]. On the other hand, PACAP and VIP potently induce differentiation of embryonic stem (ES) cells into neuronal lineage. Treatment of ES cells with PACAP or VIP induced neuronal marker expression, neurite outgrowth, and initiation of electrophysiological activity [22].

After early differentiation of stem cells into neuronal lineage, guidance of growing axons to specific location and formation of complicated neuronal networks represents one important aspect of neuronal differentiation. Growing axons navigate by sensing chemical cues at their growth cones and modulate intracellular cyclic nucleotide and $\mathrm{Ca}^{2+}$ levels to determine the direction of axon growth. Chemokines play an important role in either attracting or repulsing growth cones. For instance, the chemokine stromal-derived factor 1 (SDF-1) acts on its cognate receptor CXCR4 and guides axon growth [23]. When applied to isolated cerebellar granule cells, both SDF-1 and baclofen (an agonist of $\mathrm{GABA}_{\mathrm{B}}$ receptor) showed marked repulsive turning of growth cones [23]. Both SDF-1 and baclofen signals through $\mathrm{G}_{\mathrm{i}}$ to reduce intracellular cAMP, which is required for neuronal axon attraction [24]. Importantly, targeted disruption of either SDF-1 or CXCR4 in mice resulted in defective hematopoiesis and cerebellar neuronal migration, suggesting important functions of the chemokine SDF-1 signaling in both blood and brain development [25]. Unlike SDF-1, PACAP induces growth cone attraction by activating adenylyl cyclase and elevating local cAMP levels in neurons [26]. When cells were treated with forskolin to induce global cAMP increase, 
or with PKA inhibitor, PACAP-induced growth cone attraction was completely abolished, suggesting the importance of locally induced cAMP/PKA activity on neurite outgrowth [26].

GPCR agonists function in an orchestrated way with other factors in neuronal axon guidance. For instance, netrins are bifunctional guidance cues that attract several classes of axons but repel others. The outcome of netrin signaling depends on the receptor repertoire present on target cells that transduces the netrin signal [27]. When bound with netrins, members of the Deleted in colorectal cancer (DCC) family mediate axon attraction by activating voltage-dependent $\mathrm{Ca}^{2+}$ channels (VDCCs) including L-type $\mathrm{Ca}^{2+}$ channels (LCCs), whereas DCC/UNC5 complex leads to axon repulsion [27]. Importantly, the cyclic nucleotide profile in the growth cone determines the outcome of netrin stimulation. At a high ratio of cAMP to cGMP, netrin signals axon attraction by inducing $\mathrm{Ca}^{2+}$ influx, whereas a low ratio of cAMP to cGMP inhibits $\mathrm{Ca}^{2+}$ influx and induces axon repulsion [24]. The regulation of cAMP by SDF-1, GABA and PACAP, and that of cGMP by nitric oxide (NO) signaling [28], converge at the point of netrin-induced $\mathrm{Ca}^{2+}$ influx. It is also noteworthy that UNC5H2, a member of UNC5 family, binds to activated (i.e., GTP-bound) $\mathrm{G} \alpha_{\mathrm{i} 2}$ with its cytoplasmic domain [29]. The significance of such interaction remains to be addressed, but it may regulate cAMP production and modulate axon path-finding. Taken together, the intertwining signaling network of netrin, SDF-1 and PACAP indicates extensive crosstalk between the guidance cues in order to direct precise targeting of neuronal connections. The signaling processes regulating neuronal 
differentiation and axonal guidance are summarized in Fig. 1. In general, agonist-bound GPCRs induce neuronal differentiation via various intracellular messenger systems. These signaling events orchestrate with other chemical stimuli in determining neuronal cell lineage specification, neurite outgrowth and axonal guidance.

Signaling through GPCRs also controls the differentiation of glial cells that provide support and nutrition to neurons in the nervous system. For instance, signaling through SDF-1/CXCR4 induces the differentiation of rat oligodendrocyte precursor cells into mature oligodendrocytes [30], in addition to its function in neuronal axon growth guidance. PACAP, which has been introduced above for its stimulation on neuronal differentiation, also induces astrocyte differentiation [31]. These examples indicate the important roles for $G$ protein-mediated signaling in differentiation of both neurons and their supportive cells, and implicate therapeutical potential of GPCR-targeted medicines in the treatment of neurological disorders during development and aging.

\section{The function of $G$ protein signaling in blood cell differentiation}

GPCR ligands such as chemokines are critical players in immune responses to foreign invasion, tissue damage and repair, and cancer. Supportive evidence has been well-summarized in other reviews and are beyond the scope of this article [6]. In addition to their function in regulating mature blood system, GPCRs mediate the development of blood cells by regulating their proliferation and differentiation [32]. A 
recently identified orphan GPCR, Gpr48/LGR4 appeared to be required for definitive erythropoiesis in mice. Gpr48 ${ }^{-/}$fetuses displayed transient anemia during midgestation and were defective in red blood cell development [33]. Deletion of Gpr48 reduced cell proliferation in fetal liver, with concomitant reduction in the levels of c-Myc and cyclin D1 [33]. Gpr48 signals through the $G \alpha_{\mathrm{s}}$-cAMP pathway [34]. Defective cAMP-PKA signaling leads to reduction in the level of ATF4 transcription factor [33], which is required for definitive erythropoiesis as evidenced by its deletion in mice [35]. Unfortunately, the ligand that activates Gpr48 remains to be identified.

The complement system plays an important role in innate immune response and adaptive immunity. Locally produced $\mathrm{C} 5 \mathrm{a}$ and $\mathrm{C} 3 \mathrm{a}$ anaphylatoxins stimulate $\mathrm{T}$ cell proliferation and differentiation through their specific receptors (C5aR and $\mathrm{C} 3 \mathrm{aR})$, and the downstream PI3K $\gamma$-Akt pathway [36]. Blockade of the interaction between $\mathrm{C} 5 \mathrm{a} / \mathrm{C} 3 \mathrm{a}$ and their receptors resulted in defective expression of MHC class II and costimulatory molecules in $\mathrm{T}$ cells, along with significantly reduced $\mathrm{T}$ cell responses. Whereas addition of $\mathrm{C} 5 \mathrm{a}$ or $\mathrm{C} 3 \mathrm{a}$ to $\mathrm{T}$ cells stimulated with $\mathrm{CD} 80^{-/-} \mathrm{CD} 86^{-/-}$or $\mathrm{CD} 40^{-/-}$ antigen presenting cells (APC) restored $\mathrm{T}$ cell activation [36], thus illustrating an important role of GPCR signaling in collaboration with CD28 costimulation in T cell activation and differentiation.

Peripheral cannabinoid receptor CB2 promotes myeloid leukemia [37]. The proto-oncogene CB2 is inserted with a viral sequence in murine retrovirally induced leukemias [37]. CB2 is normally expressed in B lymphocytes, but not in normal bone marrow immature myeloid precursor cells. Over-expression of CB2 in myeloid 
precursor cells blocked neutrophilic differentiation [37, 38]. Administration of MEK inhibitors, and to a lesser extent, a PI3K inhibitor, reversed the inhibition of neutrophilic differentiation by CB2 [38]. Engagement of CB2 by its ligand leads to activation of $\mathrm{G} \alpha_{\mathrm{i}}$ and downstream MEK-ERK pathway, and reduction in cAMP level. Whereas ERK pathway is mainly responsible for suppressing neutrophilic differentiation, down-regulation of cAMP is important for migration induction by the CB2 ligand 2-arachidonoylglycerol (2-AG) [39].

In general, signaling through GPCRs mediates differentiation and migration of multiple lineages of blood cells. Given the great diversity of GPCRs and intracellular signaling events, it is anticipated that additional contributions by $\mathrm{G}$ protein-mediated signaling processes to blood development will be uncovered in the future.

\section{GPCRs in the differentiation of smooth muscle cells, adipocytes and osteoblasts}

GPCRs are also implicated in the differentiation of smooth muscle cells, osteoblasts and adipocytes. Smooth muscle cell (SMC) differentiation is regulated by a complex network of signaling processes. Serum response factor (SRF) is required for SMC differentiation by transcribing SMC-specific genes [40]. RhoA was demonstrated to modulate SRF-dependent transcription and promote SMC differentiation in a cell-based study [41]. In SMC and 10T1/2 fibroblasts, sphingosine 1-phosphate (S1P), acting through its cognate GPCR-RhoA pathway, was shown to promote SMC differentiation by facilitating the nuclear localization of myocardin-related transcription factor-A (MRTF-A), a cofactor of SRF [42]. S1P also 
leads to phosphorylation and activation of Elk-1 by ERK [42]. In mesenchymal stem cells, sphingosylphosphorylcholine (SPC) was found to promote SMC differentiation through a $\mathrm{G}_{\mathrm{i} / \mathrm{o}}$-ERK pathway and in a TGF- $\beta$ dependent manner [43]. Similarly, when treated with TGF- $\beta$, together with GPCR ligands endothelin, lysophosphatidic acid and carbachol, neural progenitor cells isolated from embryonic cerebral cortex differentiate into smooth muscle cells in vitro, as evidenced by the expression of $\alpha$-smooth muscle actin and induction of smooth muscle cell morphology [44]. Inhibition of RhoA abolished endothelin-induced SMC differentiation, suggesting that the intracellular signaling mechanism might mimic that of S1P-induced SMC differentiation $[42,44]$.

Adipocytes comprise an important energy store in animals. They accumulate triacylglycerols during energy excess and release them during fasting. Therefore regulation of adipocyte differentiation and lipid accumulation is important for the maintenance of life, as well as for understanding human abnormalities like obesity. Adipocytes differentiate in response to extracelluar signals including fatty acids and peptides. GPCR41 and GPCR43 recognize short chain fatty acids acetate and propionate as their ligands [45]. Short chain fatty acids have been reported to stimulate the production of leptin in adipocytes through GPCR41- $\mathrm{G}_{\mathrm{i}}$ pathway [46]. However in a separate study, GPCR43, but not GPCR41, was found to be expressed in mouse adipose tissues [47]. Mice fed with high-fat diets up-regulated GPCR43, PPAR- $\gamma 2$ and leptin mRNA in adipose tissues. Furthermore, GPCR43 is up-regulated during adipocyte differentiation, and treatment of 3T3-L1 cells with propionate or 
acetate enhanced adipocyte differentiation [47]. The controversy among the expression patterns of GPCR41 and GPCR43, and their role in leptin secretion by adipocytes remain to be clarified [45-47]. In addition to fatty acid signaling, peptide ligands also play a critical role in leptin regulation. For example, endothelin-1 (ET-1) was shown to stimulate leptin production and lipolysis in adipocytes, mainly through activating endothelin-A receptor [48-50]. Melanocortin (ACTH and $\alpha-\mathrm{MSH}$ ) stimulates cAMP production and inhibits leptin secretion in 3T3-L1 adipocytes [51]. ET-1 also represses the expression, but stimulates acute release, of adiponectin, a molecule that has potent insulin-sensitizing effects [52]. Taken together, signaling through a variety of GPCR ligands regulates adipose tissue differentiation and energy metabolism in a coordinated manner.

Osteoblasts construct and maintain animal bone architecture during development and throughout the life span. Along with bone morphogenetic protein (BMP) and Wnt signaling, G protein-coupled signaling processes play an important role in early differentiation of osteoblasts. For instance, in addition to its function in maintaining calcium homeostasis, parathyroid hormone $(\mathrm{PTH})$ regulates bone remodeling by acting on osteoblasts and their progenitor cells [53, 54]. Intermittent treatment of rodents with PTH increased osteoblast number and bone formation [55]. PTH induces osteoblast specific osteocalcin expression, and increases the rate of bone formation, in part by inducing BMP and Wnt signaling pathways [54]. PTH also induces autocrine IGF-1 production in a cAMP dependent manner in osteoblasts cultured in vitro [56]. Prostaglandin (PG) E2 and F2 $\alpha$ also recruit and activate osteoblasts in vivo, and 
stimulate proliferation and differentiation of osteoblasts in vitro [57, 58]. Signaling through PTH- $\mathrm{G}_{\mathrm{s}} / \mathrm{G}_{\mathrm{q}}$, PGF $2 \alpha-\mathrm{G}_{\mathrm{q}}$, and lysophosphatidic acid- $\mathrm{G}_{\mathrm{i}} / \mathrm{G}_{\mathrm{q}}$ transactivates EGF receptors and stimulates downstream ERK kinase that is required for osteoblast proliferation and differentiation [59]. These findings highlight the crucial roles of GPCRs in osteoblast differentiation and bone maintenance.

\section{Conclusions}

GPCRs and their signaling targets function in diverse systems and stages of life, such as homeostasis, neuronal sensory and signal transmission, and as reviewed in this article, differentiation of various cell lineages during development and adult life. The important functions of GPCRs in cellular differentiation are summarized in Table 1. Despite of the complex ligand-receptor combinations function on various cell types, they recruit common intracellular signaling pathways to control the differentiation process. For instance, cAMP-PKA signaling is required for the differentiation of neurons [26], red blood cells [33], neutrophils [37, 38], and osteoblasts [56]. Activation of ERK MAPK promotes the differentiation of neurons [9], smooth muscle cells [42], and osteoblasts [59], but inhibits neutrophilic differentiation [38]. Adding onto the recruitment of common signaling process for the differentiation of different cell lineages, the same ligand-receptor axis functions during different stages of cell differentiation, as in the case of SDF-1 in promoting differentiation of ES cells into neurons [22], and later on regulating axonal guidance in "more differentiated" neurons [26]. Cellular differentiation often involves concomitant withdrawal from cell 
cycle and entry of senescence. G protein-coupled pathways have also been suggested to play important roles in controlling cellular proliferation [60], suggesting the pluripotency of GPCRs and their downstream signaling molecules during cellular proliferation and differentiation.

In most cases, GPCRs do not signal alone in cell differentiation, but orchestrate with other families of receptors and intracellular pathways. An example of such is in the guidance of neuronal axon growth, where ligands of GPCRs (SDF-1, PACAP) regulate intracellular cAMP levels in growth cones, and determine the outcome of netrin signaling on growth cone movement [23-27, 61, 62]. The crosstalk of GPCR and other signaling networks apparently contributes to the precise temporal and spatial regulation of the differentiation process.

Increasing knowledge has been deposited into the daunting pool of GPCR signaling database owing to the efforts of the science community. These include the findings that demonstrate the localization of GPCRs and their signaling components in lipid rafts and caveolae [63], dimerization of GPCRs [64], and trans-activation of receptor tyrosine kinases by GPCRs [65]. In the case of cell differentiation, examples of novel GPCR signaling mechanism include transactivation of TrkA by purinergic P2Y2 receptor [12], and mediation of partial NGF signaling by $\mathrm{G}_{\mathrm{i} / \mathrm{o}}$ proteins $[14,17$, 18]. With new discoveries in the signaling mechanisms of GPCRs and novel ligands for orphan receptors, we will undoubtedly appreciate the significance of $\mathrm{G}$ protein-linked signaling in the differentiation of various cell lineages and development of tissues and organs. 


\section{Acknowledgements}

This work was supported in part by grants from the Research Grants Council of Hong

Kong (HKUST 6420/05M, 6443/06M and 1/06C), the University Grants Committee (AoE/B-15/01), and the Hong Kong Jockey Club. 


\section{References}

[1] D.K. Vassilatis, J.G. Hohmann, H. Zeng, F. Li, J.E. Ranchalis, M.T. Mortrud, A. Brown, S.S. Rodriguez, J.R. Weller, A.C. Wright, J.E. Bergmann, and G.A. Gaitanaris (2003) The $G$ protein-coupled receptor repertoires of human and mouse, Proc Natl Acad Sci U S A 100(8), 4903-8.

[2] K.L. Pierce, R.T. Premont, and R.J. Lefkowitz (2002) Seven-transmembrane receptors, Nat Rev Mol Cell Biol 3(9), 639-50.

[3] N. Mizuno and H. Itoh (2009) Functions and regulatory mechanisms of Gq-signaling pathways, Neurosignals 17(1), 42-54.

[4] N. Suzuki, N. Hajicek, and T. Kozasa (2009) Regulation and physiological functions of G12/13-mediated signaling pathways, Neurosignals 17(1), 55-70.

[5] R.R. Gainetdinov, R.T. Premont, L.M. Bohn, R.J. Lefkowitz, and M.G. Caron (2004) Desensitization of $G$ protein-coupled receptors and neuronal functions, Annu Rev Neurosci 27, 107-44.

[6] S. Singh, A. Sadanandam, and R.K. Singh (2007) Chemokines in tumor angiogenesis and metastasis, Cancer Metastasis Rev 26(3-4), 453-67.

[7] M.E. Anderson, L.S. Higgins, and H. Schulman (2006) Disease mechanisms and emerging therapies: protein kinases and their inhibitors in myocardial disease, Nat Clin Pract Cardiovasc Med 3(8), 437-45.

[8] M.V. Chao (2003) Neurotrophins and their receptors: a convergence point for many signalling pathways, Nat Rev Neurosci 4(4), 299-309.

[9] D.B. Arthur, K. Akassoglou, and P.A. Insel (2005) P2Y2 receptor activates nerve growth factor/TrkA signaling to enhance neuronal differentiation, Proc Natl Acad Sci U S A 102(52), 19138-43.

[10] D.B. Arthur, S. Georgi, K. Akassoglou, and P.A. Insel (2006) Inhibition of apoptosis by P2Y2 receptor activation: novel pathways for neuronal survival, J Neurosci 26(14), 3798-804.

[11] S. Nakanishi and M. Okazawa (2006) Membrane potential-regulated $\mathrm{Ca}^{2+}$ signalling in development and maturation of mammalian cerebellar granule cells, J Physiol 575(Pt 2), 389-95.

[12] D.B. Arthur, K. Akassoglou, and P.A. Insel (2006) P2Y2 and TrkA receptors interact with Src family kinase for neuronal differentiation, Biochem Biophys Res Commun 347(3), 678-82.

[13] R.D. Fields and G. Burnstock (2006) Purinergic signalling in neuron-glia interactions, Nat Rev Neurosci 7(6), 423-36.

[14] E.H. Wu and Y.H. Wong (2005) Involvement of $\mathrm{G}_{\mathrm{i} / \mathrm{o}}$ proteins in nerve growth factor-stimulated phosphorylation and degradation of tuberin in PC-12 cells and cortical neurons, Mol Pharmacol 67(4), 1195-205.

[15] E.H. Wu and Y.H. Wong (2005) Pertussis toxin-sensitive $\mathrm{G}_{\mathrm{i} / \mathrm{o}}$ proteins are involved in nerve growth factor-induced pro-survival Akt signaling cascade in PC12 cells, Cell Signal 17(7), 881-90.

[16] E.H. Wu and Y.H. Wong (2006) Activation of muscarinic M4 receptor augments NGF-induced pro-survival Akt signaling in PC12 cells, Cell Signal 
18(3), 285-93.

[17] L.Y. Yung, P.H. Tso, E.H. Wu, J.C. Yu, N.Y. Ip, and Y.H. Wong (2008) Nerve growth factor-induced stimulation of p38 mitogen-activated protein kinase in PC12 cells is partially mediated via $\mathrm{G}_{\mathrm{i} / \mathrm{o}}$ proteins, Cell Signal 20(8), 1538-44.

[18] P.H. Tso, C.J. Morris, L.Y. Yung, N.Y. Ip, and Y.H. Wong (2008) Multiple G Proteins Participate in Nerve Growth Factor-Induced Activation of c-Jun N-terminal Kinases in PC12 Cells, Neurochem Res.

[19] A. Arimura (1998) Perspectives on pituitary adenylate cyclase activating polypeptide (PACAP) in the neuroendocrine, endocrine, and nervous systems, Jpn J Physiol 48(5), 301-31.

[20] D. Vaudry, B.J. Gonzalez, M. Basille, L. Yon, A. Fournier, and H. Vaudry (2000) Pituitary adenylate cyclase-activating polypeptide and its receptors: from structure to functions, Pharmacol Rev 52(2), 269-324.

[21] A. Nicot and E. DiCicco-Bloom (2001) Regulation of neuroblast mitosis is determined by PACAP receptor isoform expression, Proc Natl Acad Sci U S A 98(8), 4758-63.

[22] M. Cazillis, B.J. Gonzalez, C. Billardon, A. Lombet, A. Fraichard, J. Samarut, P. Gressens, H. Vaudry, and W. Rostene (2004) VIP and PACAP induce selective neuronal differentiation of mouse embryonic stem cells, Eur J Neurosci 19(4), 798-808.

[23] Y. Xiang, Y. Li, Z. Zhang, K. Cui, S. Wang, X.B. Yuan, C.P. Wu, M.M. Poo, and S. Duan (2002) Nerve growth cone guidance mediated by G protein-coupled receptors, Nat Neurosci 5(9), 843-8.

[24] M. Nishiyama, A. Hoshino, L. Tsai, J.R. Henley, Y. Goshima, M. Tessier-Lavigne, M.M. Poo, and K. Hong (2003) Cyclic AMP/GMP-dependent modulation of $\mathrm{Ca}^{2+}$ channels sets the polarity of nerve growth-cone turning, Nature 423(6943), 990-5.

[25] Y.R. Zou, A.H. Kottmann, M. Kuroda, I. Taniuchi, and D.R. Littman (1998) Function of the chemokine receptor CXCR4 in haematopoiesis and in cerebellar development, Nature 393(6685), 595-9.

[26] C. Guirland, K.B. Buck, J.A. Gibney, E. DiCicco-Bloom, and J.Q. Zheng (2003) Direct cAMP signaling through G-protein-coupled receptors mediates growth cone attraction induced by pituitary adenylate cyclase-activating polypeptide, J Neurosci 23(6), 2274-83.

[27] J. Round and E. Stein (2007) Netrin signaling leading to directed growth cone steering, Curr Opin Neurobiol 17(1), 15-21.

[28] K.S. Madhusoodanan and F. Murad (2007) NO-cGMP signaling and regenerative medicine involving stem cells, Neurochem Res 32(4-5), 681-94.

[29] K. Komatsuzaki, S. Dalvin, and T.B. Kinane (2002) Modulation of $\mathrm{G \alpha}_{\mathrm{i} 2}$ signaling by the axonal guidance molecule UNC5H2, Biochem Biophys Res Commun 297(4), 898-905.

[30] S. Maysami, D. Nguyen, F. Zobel, C. Pitz, S. Heine, M. Hopfner, and M. Stangel (2006) Modulation of rat oligodendrocyte precursor cells by the chemokine CXCL12, Neuroreport 17(11), 1187-90. 
[31] S. Shioda, H. Ohtaki, T. Nakamachi, K. Dohi, J. Watanabe, S. Nakajo, S. Arata, S. Kitamura, H. Okuda, F. Takenoya, and Y. Kitamura (2006) Pleiotropic functions of PACAP in the CNS: neuroprotection and neurodevelopment, Ann N Y Acad Sci 1070, 550-60.

[32] Y. Su, M.K. Ho, and Y.H. Wong (2009) A hematopoietic perspective on the promiscuity and specificity of $\mathrm{G} \alpha_{16}$ signaling, Neurosignals $17(1), 71-81$.

[33] H. Song, J. Luo, W. Luo, J. Weng, Z. Wang, B. Li, D. Li, and M. Liu (2008) Inactivation of G-protein coupled receptor 48 (Gpr48/Lgr4) impairs definitive erythropoiesis at midgestation through downregulation of ATF4 signaling pathway, J Biol Chem.

[34] Y. Gao, K. Kitagawa, M. Shimada, C. Uchida, T. Hattori, T. Oda, and M. Kitagawa (2006) Generation of a constitutively active mutant of human GPR48/LGR4, a G-protein-coupled receptor, Hokkaido Igaku Zasshi 81(2), 101-5, 107, 109.

[35] H.C. Masuoka and T.M. Townes (2002) Targeted disruption of the activating transcription factor 4 gene results in severe fetal anemia in mice, Blood 99(3), 736-45.

[36] M.G. Strainic, J. Liu, D. Huang, F. An, P.N. Lalli, N. Muqim, V.S. Shapiro, G.R. Dubyak, P.S. Heeger, and M.E. Medof (2008) Locally produced complement fragments $\mathrm{C} 5 \mathrm{a}$ and $\mathrm{C} 3 \mathrm{a}$ provide both costimulatory and survival signals to naive $\mathrm{CD}^{+} \mathrm{T}$ cells, Immunity $28(3), 425-35$.

[37] M.A. Jorda, N. Rayman, P. Valk, E. De Wee, and R. Delwel (2003) Identification, characterization, and function of a novel oncogene: the peripheral cannabinoid receptor Cb2, Ann N Y Acad Sci 996, 10-6.

[38] M.A. Jorda, B. Lowenberg, and R. Delwel (2003) The peripheral cannabinoid receptor $\mathrm{Cb} 2$, a novel oncoprotein, induces a reversible block in neutrophilic differentiation, Blood 101(4), 1336-43.

[39] M. Alberich Jorda, N. Rayman, M. Tas, S.E. Verbakel, N. Battista, K. van Lom, B. Lowenberg, M. Maccarrone, and R. Delwel (2004) The peripheral cannabinoid receptor $\mathrm{Cb} 2$, frequently expressed on AML blasts, either induces a neutrophilic differentiation block or confers abnormal migration properties in a ligand-dependent manner, Blood 104(2), 526-34.

[40] S. Kim, H.S. Ip, M.M. Lu, C. Clendenin, and M.S. Parmacek (1997) A serum response factor-dependent transcriptional regulatory program identifies distinct smooth muscle cell sublineages, Mol Cell Biol 17(4), 2266-78.

[41] C.P. Mack, A.V. Somlyo, M. Hautmann, A.P. Somlyo, and G.K. Owens (2001) Smooth muscle differentiation marker gene expression is regulated by RhoA-mediated actin polymerization, J Biol Chem 276(1), 341-7.

[42] K. Lockman, J.S. Hinson, M.D. Medlin, D. Morris, J.M. Taylor, and C.P. Mack (2004) Sphingosine 1-phosphate stimulates smooth muscle cell differentiation and proliferation by activating separate serum response factor co-factors, J Biol Chem 279(41), 42422-30.

[43] E.S. Jeon, H.J. Moon, M.J. Lee, H.Y. Song, Y.M. Kim, Y.C. Bae, J.S. Jung, and J.H. Kim (2006) Sphingosylphosphorylcholine induces differentiation of 
human mesenchymal stem cells into smooth-muscle-like cells through a TGF-beta-dependent mechanism, J Cell Sci 119(Pt 23), 4994-5005.

[44] R. Morishita, K. Nagata, H. Ito, H. Ueda, M. Asano, H. Shinohara, K. Kato, and T. Asano (2007) Expression of smooth muscle cell-specific proteins in neural progenitor cells induced by agonists of $\mathrm{G}$ protein-coupled receptors and transforming growth factor-beta, J Neurochem 101(4), 1031-40.

[45] A.J. Brown, S.M. Goldsworthy, A.A. Barnes, M.M. Eilert, L. Tcheang, D. Daniels, A.I. Muir, M.J. Wigglesworth, I. Kinghorn, N.J. Fraser, N.B. Pike, J.C. Strum, K.M. Steplewski, P.R. Murdock, J.C. Holder, F.H. Marshall, P.G. Szekeres, S. Wilson, D.M. Ignar, S.M. Foord, A. Wise, and S.J. Dowell (2003) The Orphan G protein-coupled receptors GPR41 and GPR43 are activated by propionate and other short chain carboxylic acids, J Biol Chem 278(13), 11312-9.

[46] Y. Xiong, N. Miyamoto, K. Shibata, M.A. Valasek, T. Motoike, R.M. Kedzierski, and M. Yanagisawa (2004) Short-chain fatty acids stimulate leptin production in adipocytes through the $G$ protein-coupled receptor GPR41, Proc Natl Acad Sci U S A 101(4), 1045-50.

[47] Y.H. Hong, Y. Nishimura, D. Hishikawa, H. Tsuzuki, H. Miyahara, C. Gotoh, K.C. Choi, D.D. Feng, C. Chen, H.G. Lee, K. Katoh, S.G. Roh, and S. Sasaki (2005) Acetate and propionate short chain fatty acids stimulate adipogenesis via GPCR43, Endocrinology 146(12), 5092-9.

[48] Y. Xiong, H. Tanaka, J.A. Richardson, S.C. Williams, C.A. Slaughter, M. Nakamura, J.L. Chen, and M. Yanagisawa (2001) Endothelin-1 stimulates leptin production in adipocytes, J Biol Chem 276(30), 28471-7.

[49] C.C. Juan, L.W. Chang, S.W. Huang, C.L. Chang, C.Y. Lee, Y. Chien, Y.P. Hsu, P.H. Ho, Y.C. Chen, and L.T. Ho (2006) Effect of endothelin-1 on lipolysis in rat adipocytes, Obesity (Silver Spring) 14(3), 398-404.

[50] I. Bhattacharya and A. Ullrich (2006) Endothelin-1 inhibits adipogenesis: role of phosphorylation of Akt and ERK1/2, FEBS Lett 580(24), 5765-71.

[51] D. Norman, A.M. Isidori, V. Frajese, M. Caprio, S.L. Chew, A.B. Grossman, A.J. Clark, G. Michael Besser, and A. Fabbri (2003) ACTH and alpha-MSH inhibit leptin expression and secretion in 3T3-L1 adipocytes: model for a central-peripheral melanocortin-leptin pathway, Mol Cell Endocrinol 200(1-2), 99-109.

[52] C.C. Juan, T.Y. Chuang, C.L. Chang, S.W. Huang, and L.T. Ho (2007) Endothelin-1 regulates adiponectin gene expression and secretion in 3T3-L1 adipocytes via distinct signaling pathways, Endocrinology 148(4), 1835-42.

[53] P. Christiansen (2001) The skeleton in primary hyperparathyroidism: a review focusing on bone remodeling, structure, mass, and fracture, APMIS Suppl (102), 1-52.

[54] M. Ogita, M.T. Rached, E. Dworakowski, J.P. Bilezikian, and S. Kousteni (2008) Differentiation and proliferation of periosteal osteoblast progenitors are differentially regulated by estrogens and intermittent parathyroid hormone administration, Endocrinology 149(11), 5713-23. 
[55] H. Dobnig and R.T. Turner (1995) Evidence that intermittent treatment with parathyroid hormone increases bone formation in adult rats by activation of bone lining cells, Endocrinology 136(8), 3632-8.

[56] T.L. McCarthy, M. Centrella, and E. Canalis (1990) Cyclic AMP induces insulin-like growth factor I synthesis in osteoblast-enriched cultures, J Biol Chem 265(26), 15353-6.

[57] Y.F. Ma, X.J. Li, W.S. Jee, J. McOsker, X.G. Liang, R. Setterberg, and S.Y. Chow (1995) Effects of prostaglandin E2 and F2 alpha on the skeleton of osteopenic ovariectomized rats, Bone 17(6), 549-54.

[58] L.D. Quarles, D.M. Haupt, G. Davidai, and J.P. Middleton (1993)

Prostaglandin F2 alpha-induced mitogenesis in MC3T3-E1 osteoblasts: role of protein kinase-C-mediated tyrosine phosphorylation, Endocrinology 132(4), 1505-13.

[59] C.F. Lai, L. Chaudhary, A. Fausto, L.R. Halstead, D.S. Ory, L.V. Avioli, and S.L. Cheng (2001) Erk is essential for growth, differentiation, integrin expression, and cell function in human osteoblastic cells, J Biol Chem 276(17), 14443-50.

[60] E. Rozengurt (2007) Mitogenic signaling pathways induced by $\mathrm{G}$ protein-coupled receptors, J Cell Physiol 213(3), 589-602.

[61] Q. Ma, D. Jones, P.R. Borghesani, R.A. Segal, T. Nagasawa, T. Kishimoto, R.T. Bronson, and T.A. Springer (1998) Impaired B-lymphopoiesis, myelopoiesis, and derailed cerebellar neuron migration in CXCR4- and SDF-1-deficient mice, Proc Natl Acad Sci U S A 95(16), 9448-53.

[62] Q. Lu, E.E. Sun, R.S. Klein, and J.G. Flanagan (2001) Ephrin-B reverse signaling is mediated by a novel PDZ-RGS protein and selectively inhibits G protein-coupled chemoattraction, Cell 105(1), 69-79.

[63] H.H. Patel, F. Murray, and P.A. Insel (2008) G-protein-coupled receptor-signaling components in membrane raft and caveolae microdomains, Handb Exp Pharmacol (186), 167-84.

[64] V.V. Gurevich and E.V. Gurevich (2008) How and why do GPCRs dimerize?, Trends Pharmacol Sci 29(5), 234-40.

[65] N. Delcourt, J. Bockaert, and P. Marin (2007) GPCR-jacking: from a new route in RTK signalling to a new concept in GPCR activation, Trends Pharmacol Sci 28(12), 602-7.

[66] S.H. Chalasani, K.A. Sabelko, M.J. Sunshine, D.R. Littman, and J.A. Raper (2003) A chemokine, SDF-1, reduces the effectiveness of multiple axonal repellents and is required for normal axon pathfinding, J Neurosci 23(4), 1360-71.

[67] F. He, Z.H. Qiao, J. Cai, W. Pierce, D.C. He, and Z.H. Song (2007) Involvement of the $90-\mathrm{kDa}$ heat shock protein (Hsp-90) in CB2 cannabinoid receptor-mediated cell migration: a new role of Hsp-90 in migration signaling of a G protein-coupled receptor, Mol Pharmacol 72(5), 1289-300.

[68] M. Wan, C. Yang, J. Li, X. Wu, H. Yuan, H. Ma, X. He, S. Nie, C. Chang, and X. Cao (2008) Parathyroid hormone signaling through low-density 
lipoprotein-related protein 6, Genes Dev 22(21), 2968-79.

[69] I. Ahmed, D. Gesty-Palmer, M.K. Drezner, and L.M. Luttrell (2003)

Transactivation of the epidermal growth factor receptor mediates parathyroid hormone and prostaglandin F2 alpha-stimulated mitogen-activated protein kinase activation in cultured transgenic murine osteoblasts, Mol Endocrinol 17(8), 1607-21. 
Table 1. Function of GPCRs in cellular differentiation

\begin{tabular}{|c|c|c|c|c|c|}
\hline Cell lineage & Ligand & Receptor & $\begin{array}{l}\text { Signaling } \\
\text { components }\end{array}$ & Function & References \\
\hline Neuron & ATP/UTP & $\mathrm{P} 2 \mathrm{Y} 2$ & $\begin{array}{l}\text { SFK-TrkA-ERK } \\
\mathrm{G}_{\mathrm{q}}-\mathrm{IP}_{3}-\mathrm{Ca}^{2+}\end{array}$ & Survival, differentiation & {$[9,10,12]$} \\
\hline Neuron & $\begin{array}{l}\text { PACAP/ } \\
\text { VIP }\end{array}$ & VPAC & cAMP, $\mathrm{Ca}^{2+}$ & $\begin{array}{l}\text { Differentiation, axon } \\
\text { guidance }\end{array}$ & {$[22,26]$} \\
\hline Neuron & SDF-1 & CXCR4 & cAMP, $\mathrm{Ca}^{2+}$ & Axon guidance & {$[23,25,66]$} \\
\hline Erythrocyte & & Gpr48 & $\begin{array}{l}\text { cAMP, PKA, } \\
\text { ATF4 }\end{array}$ & Definitive erythropoiesis & {$[33-35]$} \\
\hline $\begin{array}{l}\mathrm{T} \\
\text { lymphocyte }\end{array}$ & $\mathrm{C} 5 \mathrm{a}, \mathrm{C} 3 \mathrm{a}$ & $\begin{array}{l}\text { C5aR, } \\
\text { C3aR }\end{array}$ & $\mathrm{PI} 3 \mathrm{~K} \gamma, \mathrm{Akt}$ & Differentiation, activation & {$[36]$} \\
\hline Neutrophil & $2-\mathrm{AG}$ & $\mathrm{Cb} 2$ & $\begin{array}{l}\mathrm{G}_{\mathrm{i}}, \mathrm{cAMP}, \mathrm{ERK} \\
\mathrm{HSP} 90\end{array}$ & $\begin{array}{l}\text { Anti-differentiation, } \\
\text { migration }\end{array}$ & {$[37-39,67]$} \\
\hline $\begin{array}{l}\text { Smooth } \\
\text { muscle cell }\end{array}$ & S1P & Edg & $\begin{array}{l}\text { RhoA, ERK, } \\
\text { MRTF-A, Elk-1 }\end{array}$ & Proliferation, differentiation & {$[41,42]$} \\
\hline $\begin{array}{l}\text { Smooth } \\
\text { muscle cell }\end{array}$ & SPC & & $\mathrm{G}_{\mathrm{i} / \mathrm{o}}, \mathrm{ERK}$ & Differentiation & {$[43]$} \\
\hline Adipocyte & $\begin{array}{l}\text { Short } \\
\text { fatty acids }\end{array}$ & $\begin{array}{l}\text { GPCR41/ } \\
43\end{array}$ & $\mathrm{G}_{\mathrm{i}}$ & $\begin{array}{l}\text { Differentiation, leptin } \\
\text { production }\end{array}$ & {$[45,47]$} \\
\hline Adipocyte & ET-1 & $\mathrm{ET}_{\mathrm{A}}$ & ERK, Akt & $\begin{array}{l}\text { Leptin production, lipolysis, } \\
\text { anti-differentiation }\end{array}$ & {$[48-50]$} \\
\hline Adipocyte & $\begin{array}{l}\text { Melanoco } \\
\text { rtin }\end{array}$ & $\begin{array}{l}\mathrm{MC} 2 \mathrm{R} / \mathrm{M} \\
\mathrm{C} 5 \mathrm{R}\end{array}$ & cAMP & Inhibit leptin secretion & {$[51]$} \\
\hline Osteoblast & PTH & PTH1R & $\begin{array}{l}\text { cAMP, ERK, } \\
\text { BMP, Wnt }\end{array}$ & $\begin{array}{l}\text { Differentiation, } \\
\text { anti-proliferation }\end{array}$ & {$[54,68]$} \\
\hline Osteoblast & PGF $2 \alpha$ & PGF2Ar & $\mathrm{G}_{\mathrm{q}}, \mathrm{EGFR}, \mathrm{ERK}$ & Proliferation, differentiation & {$[59,69]$} \\
\hline
\end{tabular}


Figure 1. Regulation of neuronal differentiation and axon guidance. Neuronal differentiation is orchestrated by crosstalk between different extracelluar ligand-induced signals. $\mathrm{G}_{\mathrm{i} / \mathrm{o}}$ mediates part of the NGF-induced MAPK and Akt activation. Nucleotide-activated purinergic receptor P2Y2 potentiates NGF signaling through SFK, and induces $\mathrm{Ca}^{2+}$ signaling in a $\mathrm{G}_{\mathrm{q}}$-dependent manner. Netrin activates DCC to induce $\mathrm{Ca}^{2+}$ influx through LCC. PACAP and VIP induce neuronal differentiation by activating cAMP and $\mathrm{Ca}^{2+}$ mediated pathways. PACAP, SDF-1 and baclofen (GABA) signal through their cognate GPCRs to regulate intracellular cAMP levels, which in turn determine the outcome of netrin signaling on LCC. 


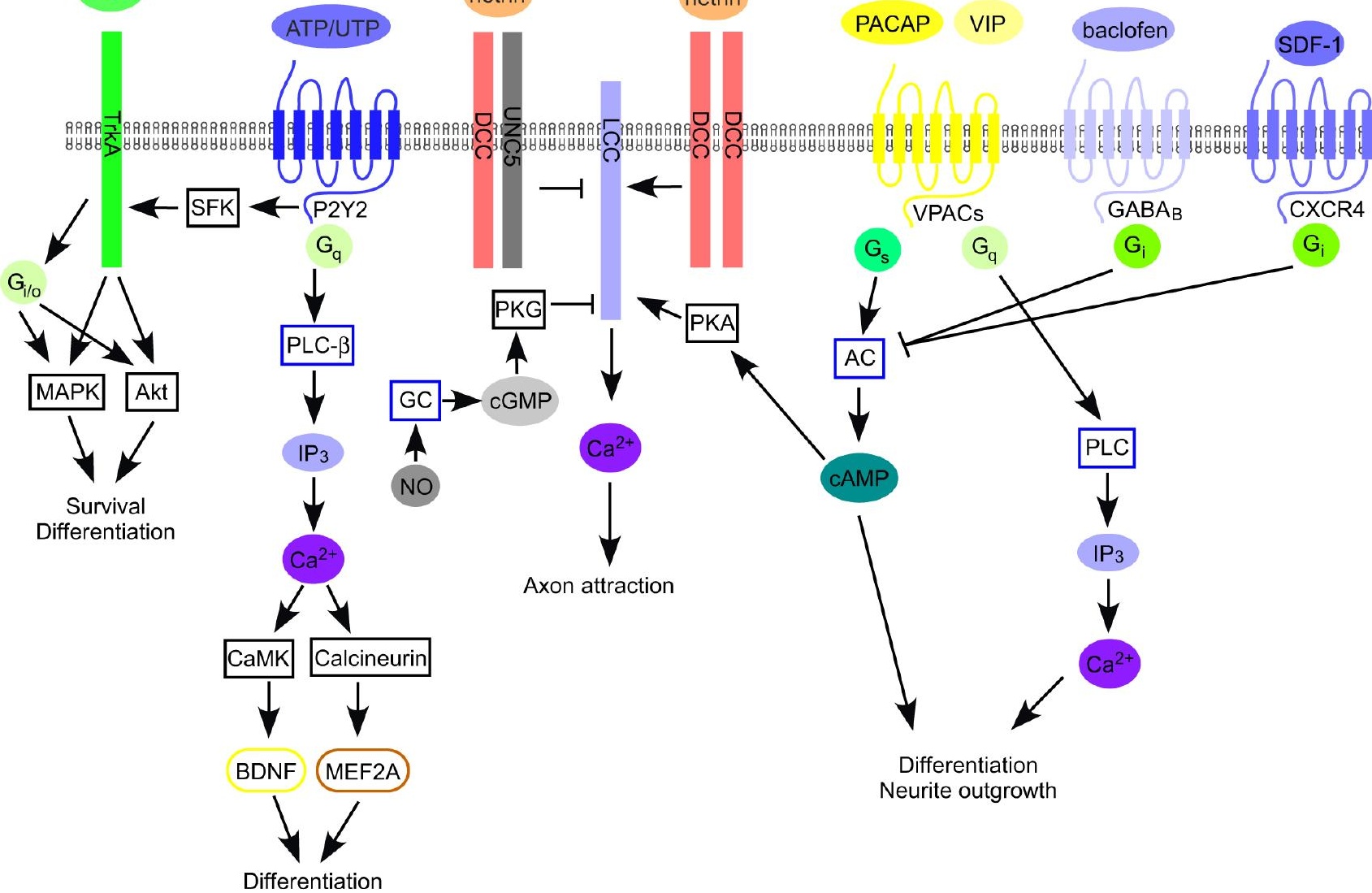

